\title{
Evolution of microstructure with increasing carbon content and its effect on mechanical properties of disordered iron-aluminium alloy
}

\author{
SHIVKUMAR KHAPLE ${ }^{1,2, * \mathbb{D}, \text { D V V SATYANARAYANA }{ }^{1} \text {, V V SATYA PRASAD }}{ }^{1}$ \\ and BRAHMA RAJU GOLLA ${ }^{2}$ \\ ${ }^{1}$ Defence Metallurgical Research Laboratory, Hyderabad 500058, India \\ ${ }^{2}$ National Institute of Technology, Warangal 506004, India \\ *Author for correspondence (sikaple@ yahoo.com)
}

MS received 17 November 2018; accepted 21 May 2019

\begin{abstract}
Correlation of microstructure and mechanical properties of hot-rolled $\mathrm{Fe}-7 \mathrm{wt} . \% \mathrm{Al}$ with varying carbon contents has been investigated in detail. The microstructures of the alloys change significantly with an increase in the carbon content. An alloy with $0.012 \mathrm{wt} . \%$ carbon shows a single ferrite phase, whereas with increase in carbon up to $0.65 \mathrm{wt} . \%$, the microstructure evolves into a dual phase consisting of ferrite and $\kappa$-pearlite. At about $1.5 \mathrm{wt} \%$ carbon, the alloy exhibits only $\kappa$-pearlite and with a further increase in carbon to $2.2 \mathrm{wt} . \%$, an additional phase starts precipitating in the form of graphite. The room temperature tensile strength of the alloy increased significantly with an increase in the carbon content, which is in agreement with the microstructure. The yield strength and hardness of the steels with different carbon contents can be correlated well with the inter-barrier spacing in different steels.
\end{abstract}

Keywords. Low-density steel; iron aluminium alloys; lightweight steels; mechanical properties.

\section{Introduction}

Disordered iron-aluminium alloys are an emerging class of low-density/lightweight steels containing aluminium in the range of $6-9$ wt. \% in steel. These $\mathrm{Fe}-\mathrm{Al}$ alloys with a disordered A2 ferrite structure have raised considerable interest due to their low-density, high ductility, cost-effective and feasibility for bulk production. These low-density and highstrength materials are envisaged in the development of an advanced lightweight ground transportation system, huge structures like bridges, tunnels and also being deemed for certain defence applications like troops carrier, armour, etc. Alternatively, they are also considered as potential candidates for steam turbines in thermal power plants [1-7]. Al being a ferrite stabilizer, reduces the austenitic loop and enhances the ferrite phase field, which results in a complete ferrite microstructure at room temperature [8-10]. This disordered ferritic (A2) phase results in good ductility, but suffers from the loss of strength compared to the other existing structural materials such as heat-resistant stainless steel [3-6]. To overcome the strength issue of these alloys, alloy modifications were attempted with $\mathrm{Mn}$ and carbon, which resulted in higher strength than the existing $\mathrm{Fe}-\mathrm{Al}$ alloys [11-13]. Nevertheless, these alloys had a setback in the form of cracking during the rolling stage.

The effect of carbon on the improvement of strength of ordered $\mathrm{Fe}_{3} \mathrm{Al}$ alloys has been reported in detail $[8,14$ 17]. However, very less work has been reported on the effect of carbon on the microstructure evolution effect, and hence, on the properties of disordered ferritic steels $[6,7]$.

Therefore, it is of current interest to explore the potential of carbon as an alloying element to enhance the strength of disordered ferritic Fe-7 wt.\% Al-based low-density steel. It is interesting to note that the density advantage of about $10 \%$ is still retained in Mn free steels as the density reduction mainly results from the addition of $\mathrm{Al}$. In the present study, the effect of carbon on the evolution of the microstructure and its impact on mechanical properties and fracture behaviour of $\mathrm{Fe}-\mathrm{Al}$-based steels containing $7 \mathrm{wt} \% \mathrm{Al}$ have been investigated and the results are presented in this paper.

\section{Experimental}

An air induction melting process was used to make five melts of low-density $\mathrm{Fe}-\mathrm{Al}$-based steel with different carbon contents, each weighing about $40 \mathrm{~kg}$. The steels containing 0.012 , $0.35,0.65,1.5$ and $2.2 \mathrm{wt} . \%$ carbon were hereafter designated as 'S1', 'S2', 'S3', 'S4' and 'S5' steels, respectively. The details of the charge preparation and melting procedure was discussed elsewhere $[6,8]$. The melt was top poured into split cast iron moulds with a diameter of $55 \mathrm{~mm}$. The hot working of the steel from ingots to $12 \mathrm{~mm}$ thick plate is described 
elsewhere $[6,8]$. The density of the steels was determined by following the Archimedes principle.

Manganese, silicon and aluminium were analysed by a wet chemical method. CC-444 Leco carbon and sulphur determinator were used to analyse carbon and sulphur. An X-ray diffractometer of Philips was used to identify the phases present in the steels. Precipitate and the matrix compositions of the steels were carried out by electron probe microanalyser (EPMA) analysis. The volume fraction of precipitates present in steels was determined using optical microscopy and Biovis Materials Plus Software. Bulk hardness was measured using a Vickers hardness machine and micro hardness was measured using a Leitz Micro hardness machine. The procedure for the calculation of the volume fraction of the phases is explained elsewhere [15-17]. The bulk hardness values were calculated from the micro hardness measurements using the rule of mixtures for the phases present. The Instron universal testing machine was used to carry out the tensile tests as per ASTM-E $8 \mathrm{M}$ standard using specimens of $4 \mathrm{~mm}$ gauge diameter and $20 \mathrm{~mm}$ gauge length. The fracture surface of tensile specimens was observed using scanning electron microscopy (SEM).

\section{Results and discussion}

\subsection{Microstructure}

The chemical composition of five steels based on Fe-7 wt.\% $\mathrm{Al}$ with different carbon contents is given in table 1. Optical micrographs depicting microstructures of these steels are shown in figure 1. Steel S1 reveals a single ferrite phase microstructure (figure 1a). However, steel S2 shows a significant amount of the second phase in the form of precipitates apart from ferrite (figure 1b). At 0.65 wt.\% carbon, the microstructure exhibits an increased amount of the second phase, which exists in the form of bands (figure 1c). When carbon content is further increased to higher levels, i.e., 1.5 and $2.2 \mathrm{wt} . \%$, the second phase in the form of very fine precipitate is observed (figure 1d and e). The precipitates being very fine, are not resolved by optical microscopy. Additionally, there is a third phase with dark contrast distributed in the matrix of steel S5 (figure 1e). Further, as illustrated by secondary electron images (figure 2), the second phase, which is in the form of small globules in the steel, S2, while in the form of bands in the steel, S3, is essentially the $\kappa$-pearlite ( $\kappa$-carbide + ferrite) phase composed of ferrite $\mathrm{Fe}-\mathrm{Al}(\alpha)$ and $\kappa$-carbides $\left(\mathrm{Fe}_{3} \mathrm{AlC}_{0.5}\right)$ as identified by X-ray diffraction (XRD) analysis (figure 3). SEM micrographs at higher magnification reveal the distribution of dense, fine spherical and the lamellar $\kappa$-carbide precipitates inside the globular $\kappa$-pearlite of steel S2, while inside the $\kappa$-pearlite bands of steel S3. Further, it can also be noted that with an increase in carbon content from 0.35 to $0.65 \mathrm{wt} . \%$, the volume fraction of $\kappa$-pearlite has increased from 12.84 to $26.04 \%$, while inter-pearlite spacing decreased from 75.20 to $8.30 \mu \mathrm{m}$.

On the other hand, steels $\mathrm{S} 4$ (figure $2 \mathrm{e}$ and $\mathrm{f}$ ) and $\mathrm{S} 5$ (figure $2 \mathrm{~g}$ and $\mathrm{h}$ ) exhibit a complete $\kappa$-pearlite structure consisting of globular $\kappa$-carbides in a ferrite matrix. It is to be pointed out that the microstructural features observed in steel S4 i.e., the complete pearlitic structure is similar to another steel containing $7.16 \% \mathrm{Al}, 1.72 \% \mathrm{C}$ and $9.98 \% \mathrm{Mn}$ [18]. Further, it is to be noted that the microstructure of steel S5 also exhibits dark coloured coarse precipitates as illustrated in figure $2 \mathrm{~g}$. The wavelengthdispersive X-ray spectroscopy (WDS) image (figure 4) and EPMA line scan (figure 5) of the dark coloured precipitate observed in steel S5 clearly indicate that they are rich in carbon and resembles one of the basic shapes of graphite. The amount of aluminium available in steel S5 is sufficient to form only about 57 volume $\%$ of $\mathrm{Fe}_{3} \mathrm{AlC}_{0.5}$ precipitates for which, the amount of carbon required is about 1.6 wt. $\%$. Therefore, the balance $0.6 \mathrm{wt} . \%$ carbon condenses as graphite. Similar observations have also been reported earlier in ferritic $\mathrm{Fe}-\mathrm{Al}$ steel [7].

\subsection{Mechanical properties}

The mechanical properties, such as hardness, specific strength and ductility of all the steels with different carbon contents are summarized in table 2 . The density of the alloys changes in the range of 7.23151-7.10318 $\mathrm{g} \mathrm{cm}^{-3}$. These steels show a considerable density reduction $(\sim 10 \%)$ compared to the traditional steel $\left(7.87324 \mathrm{~g} \mathrm{~cm}^{-3}\right)$. The micro-hardness of $\kappa$ carbide precipitates $\left(585-595 H_{\mathrm{v}}\right)$ obtained here, complies to the values reported in the literature $[8,15]$. Also, the calculated volume fraction of the precipitates complies to the

Table 1. Chemical composition of Fe-7 wt.\% Al-based steel.

\begin{tabular}{lccccc}
\hline & & \multicolumn{3}{c}{ Steel composition } \\
\cline { 3 - 6 } Steel & Nominal composition (wt.\%) & Al (wt.\%) & Si (wt.\%) & Mn (wt.\%) & S (wt.\%) \\
\hline S1 & Fe-7Al-0.012C & 6.88 & 0.18 & 0.16 & 0.004 \\
S2 & Fe-7Al-0.35C & 6.78 & 0.19 & 0.15 & 0.004 \\
S3 & Fe-7Al-0.65C & 6.98 & 0.15 & 0.12 & 0.004 \\
S4 & Fe-7Al-1.5C & 7.10 & 0.18 & 0.13 & 0.002 \\
S5 & Fe-7Al-2.2C & 7.11 & 0.16 & 0.15 & 0.65 \\
\hline
\end{tabular}



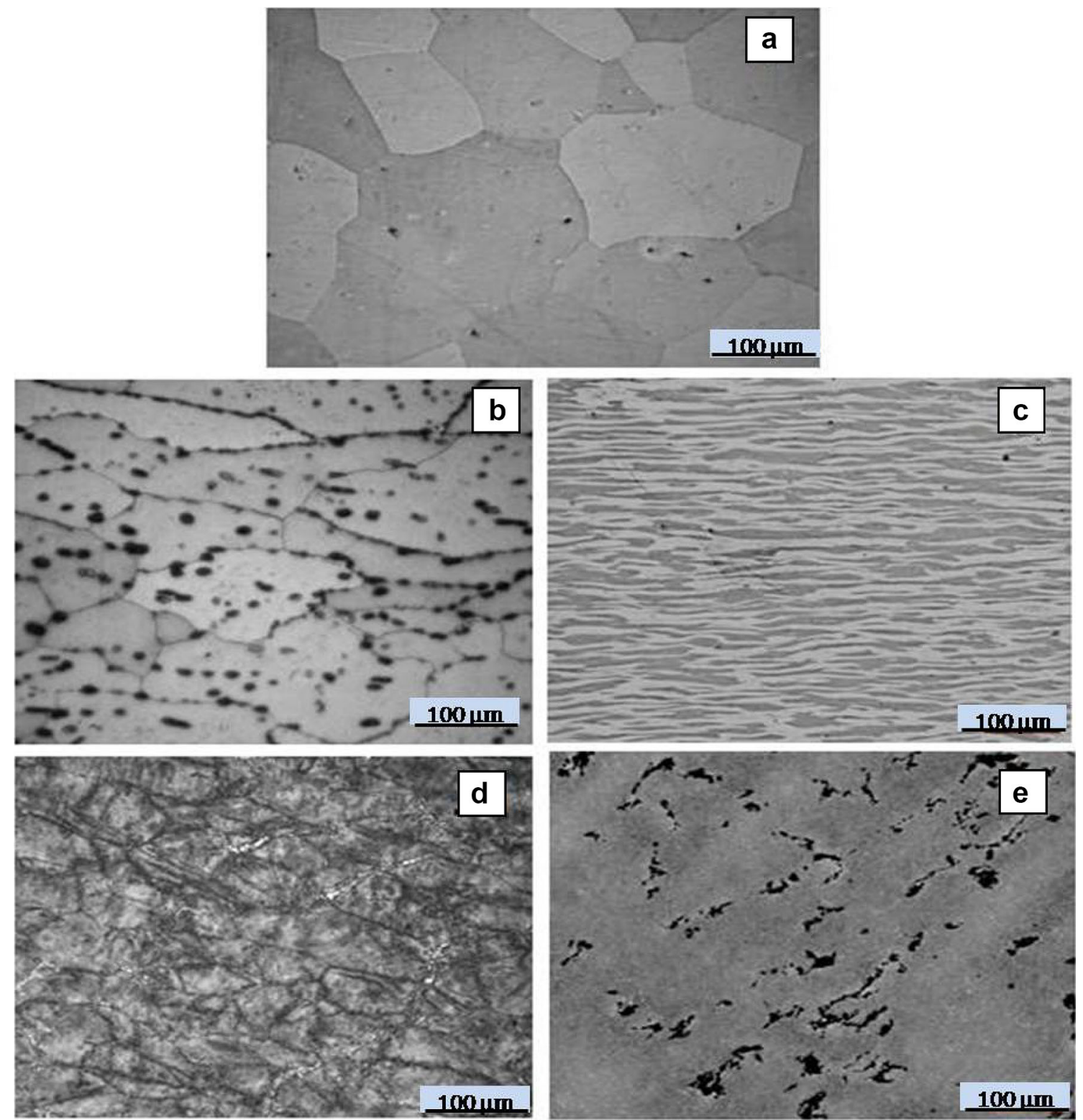

Figure 1. Optical micrographs showing the microstructure of Fe-7 wt.\% Al-based steel with (a) 0.012, (b) 0.35 , (c) 0.65 , (d) 1.5 and (e) 2.2 wt.\% carbon.

measured values for all steels. It would thus appear that most of the carbons are present as $\mathrm{Fe}_{3} \mathrm{AlC}_{0.5}$ in $\mathrm{S} 2-\mathrm{S} 4$ steels and $\mathrm{Fe}_{3} \mathrm{AlC}_{0.5}$ and graphite in steel S5 as there is very minimal solubility of carbon in the $\mathrm{Fe}-\mathrm{Al}$ matrix [8-10]. It is clear that as $\mathrm{Al}$ content in the matrix decreases, the volume fraction of the $\mathrm{Fe}_{3} \mathrm{AlC}_{0.5}$ phase increases (table 3). Since there is a depletion of $\mathrm{Al}$ from the matrix due to the formation of $\kappa$-carbide precipitates, the hardness of the matrix decreases (table 2). The bulk hardness increases with an increase in carbon up to $1.5 \mathrm{wt} . \%$ which is attributed to the increased formation of hard $\kappa$-carbide precipitates, but with a further increase in carbon up to $2.2 \mathrm{wt}$. $\%$, the increase in the hardness is not significant as it results in only minimal (3.5\%) increase in the volume fraction of hard $\mathrm{Fe}_{3} \mathrm{AlC}_{0.5}$ and, also, leads to the precipitation of a small amount of soft graphite (hardness, $\left.H_{\mathrm{v}}=10\right)$. The calculated bulk hardness is found to be only slightly lower than the measured bulk Vicker's hardness for all the steels studied. Thus, hardness values appear to follow the rule of mixtures for the present set of steels. It can be seen that specific strength increases, while ductility decreases considerably with an increase in carbon content (table 2). Since the micro-hardness of the $\kappa$-carbide precipitates is much higher than that of matrix, an increase in specific strength and bulk hardness is observed, while a decrease in elongation of all 

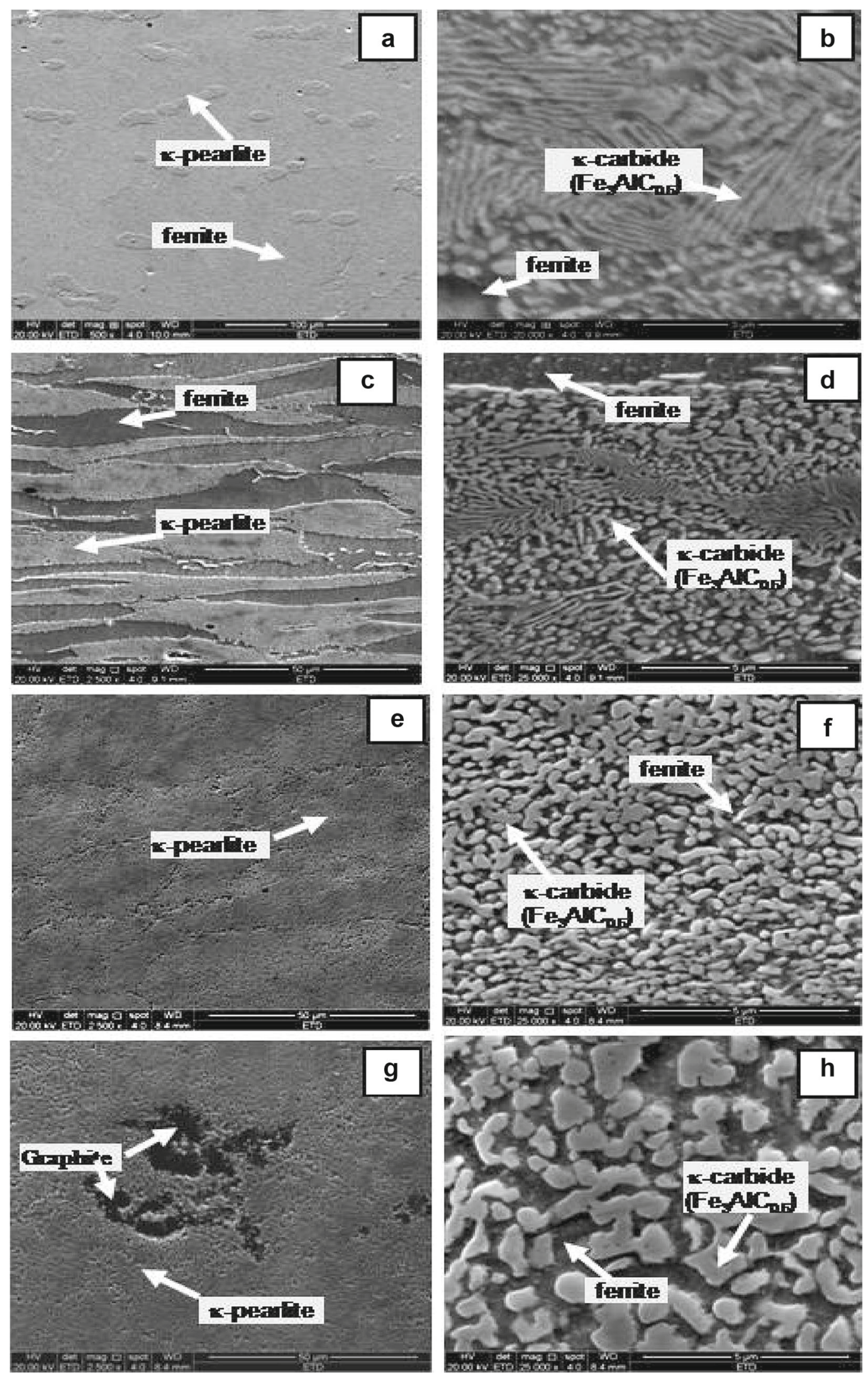

Figure 2. SEM micrographs of Fe-7 wt.\% Al-based steel S2 (a, b), steel S3 (c, d), steel S4 (e, f) and steel S5 $(\mathbf{g}, \mathbf{h})$. Micrographs $\mathbf{b}, \mathbf{d}, \mathbf{f}$ and $\mathbf{h}$ show precipitates in the steel, respectively, at higher magnification. 


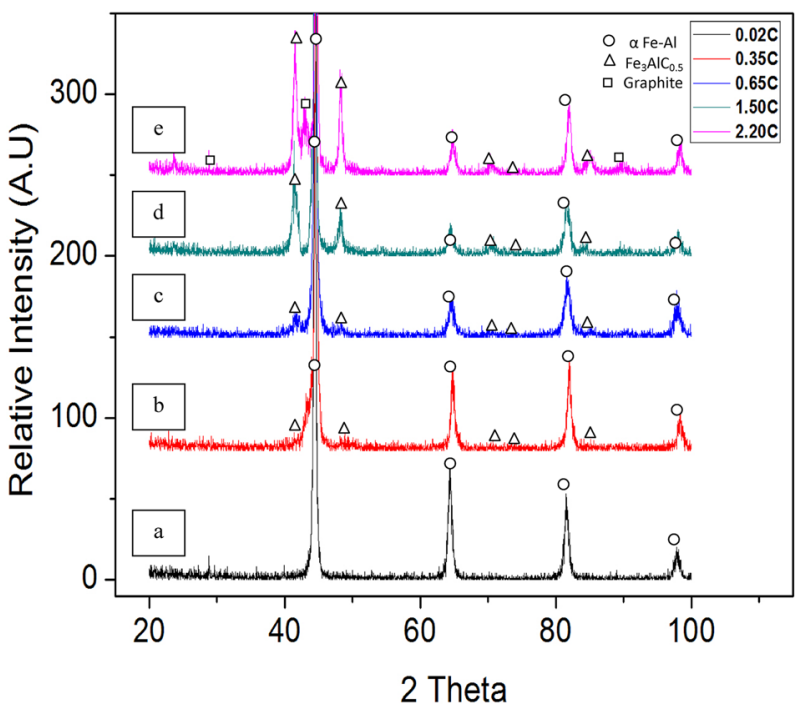

Figure 3. $\mathrm{XRD}$ traces using $\mathrm{CuK} \alpha$ radiation showing $\alpha(\mathrm{Fe}-\mathrm{Al})$ peaks of Fe-7 wt.\% Al steel with (a) 0.012, (b) 0.35, (c) 0.65, (d) 1.5 and (e) $2.2 \mathrm{wt} . \%$ carbon.
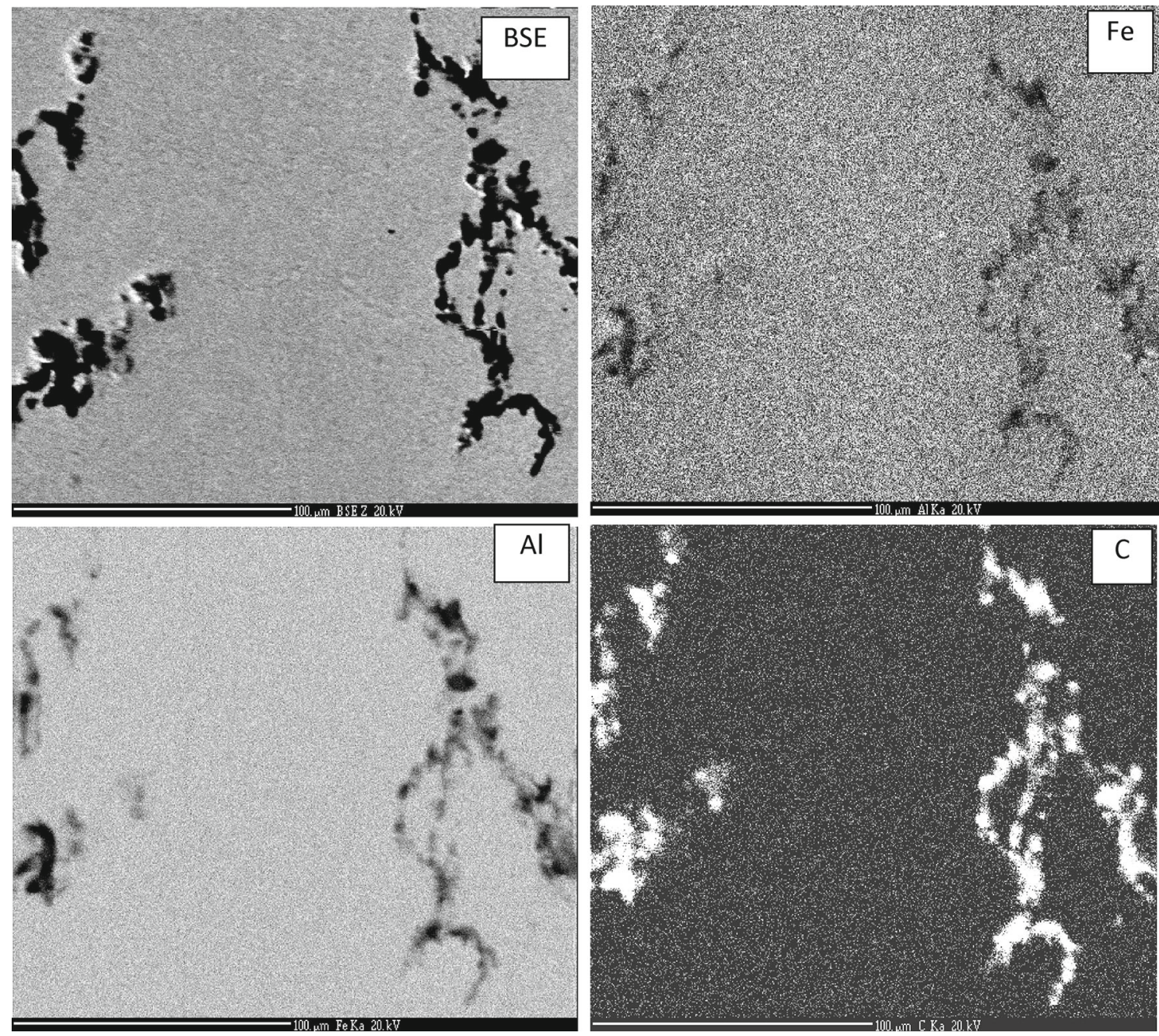

these steels with an increase in carbon content can be related to the increase in the volume percentage of $\kappa$-pearlite/hard $\kappa$-carbides. Thus, for the present steels, it appears that the hardness values follow the rule of mixture which is similar to $\mathrm{Fe}_{3} \mathrm{Al}$-based alloys containing carbon $[15,17]$.

To understand the underlying mechanism to explain the dependence of yield strength on carbon content, the HallPetch type equation of the form that relates the strength or hardness to inter-barrier spacing is considered.

$$
\begin{aligned}
\sigma_{\mathrm{y}} & =\sigma_{0}+k_{\mathrm{y}} L^{-1 / 2}, \\
H_{\mathrm{v}} & =H_{\mathrm{v} 0}+k_{\mathrm{H}} L^{-1 / 2},
\end{aligned}
$$

where $\sigma_{\mathrm{y}}$ is the yield strength and $H_{\mathrm{v}}$ the bulk Vickers hardness, $\sigma_{0}$ and $H_{\mathrm{v} 0}$ are constants related to the strength and hardness of the ferrite phase, $k_{\mathrm{y}}$ and $k_{\mathrm{H}}$ are constants which are characteristic to mean inter-barrier spacing (locking parameter) and $L$ is inter-barrier spacing. Since the microstructure

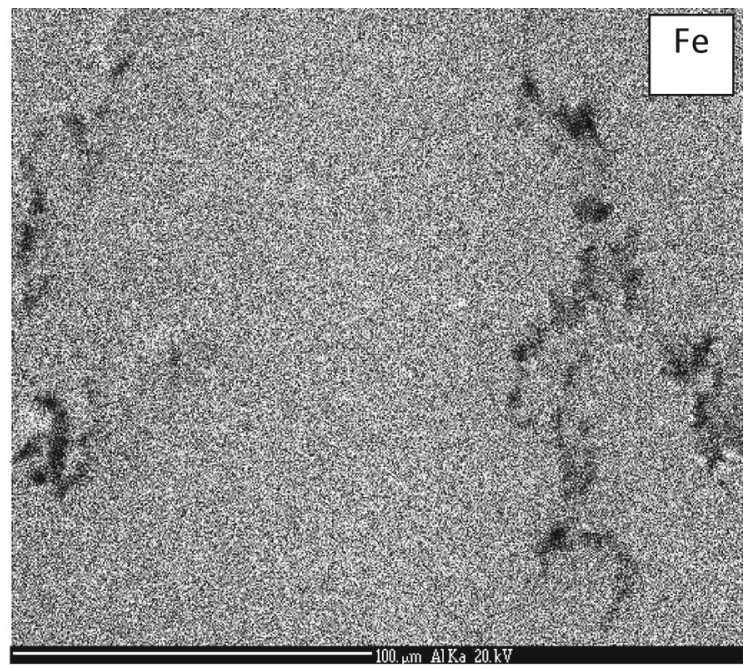

Figure 4. WDS images observed in EPMA showing distribution of elements of Fe-7 wt.\% Al-2.2 wt.\% C steel. 
of the steel evolves with carbon content as already discussed (section 3.1), from complete ferrite, through ferrite plus $\kappa$-pearlite to complete $\kappa$-pearlite and finally, to globular $\kappa$-carbides in the ferrite matrix, different types of barriers to

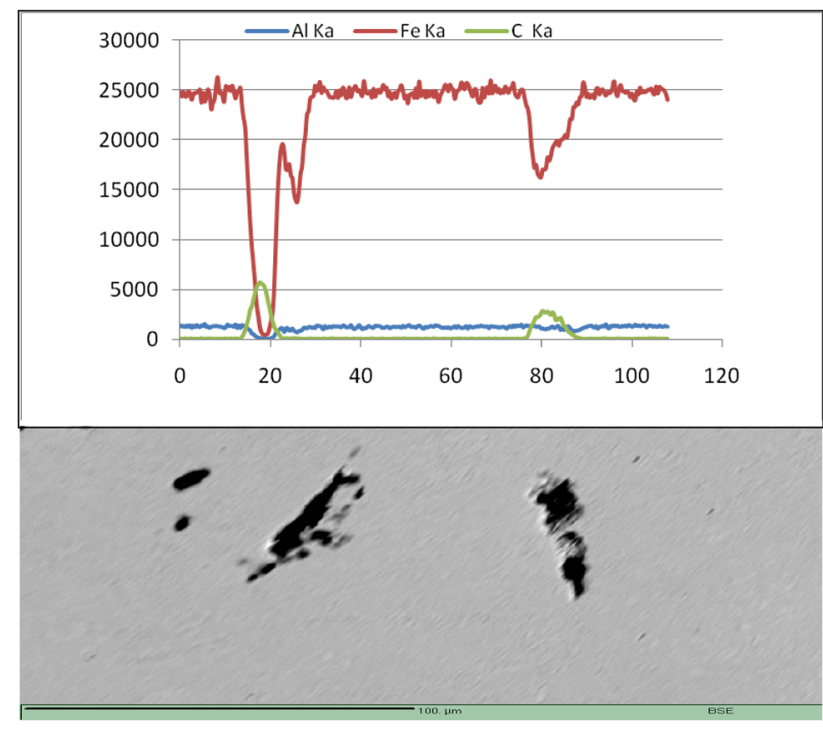

Figure 5. BSE image and line scan of EPMA observed in $\mathrm{Fe}-$ 7 wt.\% Al-2.2 wt.\% C steel. dislocation in different steels are to be considered to verify the validity of the above relationships. As shown in figure 1 and 2 as well as schematically illustrated in figure 6 , the appropriate barriers in different steels are identified as follows. In the case of steels S2 (figure 6a) and S3 (figure 6b), к-pearlite being the harder phase, the inter-pearlite phase spacing as marked in figure 6 , is considered as ' $L$ '. On the other hand, in steels S4 and $\mathrm{S} 5$, the inter-carbide $\left(\mathrm{Fe}_{3} \mathrm{AlC}_{0.5}\right)$ spacing is taken as ' $L$ '. Based on this analysis, both yield strength and bulk hardness data of different steels are plotted as a function of inter-barrier spacing as shown in figure 7 and the data are fitted according to equations ( 1 and 2 ) for yield strength and hardness, respectively. It is interesting to observe that both yield strength and hardness data correlate with the inter-barrier spacing reasonably well, thereby supporting the proposed supposition of barriers in steels with different carbon contents as well as strength or hardness dependence on inter-barrier spacing. The values of $\sigma_{0}, k_{\mathrm{y}}, H_{\mathrm{v} 0}$ and $k_{\mathrm{H}}$ of the present alloys obtained from the fitting of the data to the above equations are $\sim 435$ $\mathrm{MPa}, 245 \mathrm{MPa}, 234 H_{\mathrm{v}}$ and $110 H_{\mathrm{v}}$, respectively. The yield strength of the $\mathrm{Fe}-7 \mathrm{Al}(\alpha)$ steel i.e., steel S1 of the present study is determined to be $\sim 400 \mathrm{MPa}$, which is fairly close to the value of $\sigma_{0}$ i.e., $\sim 435 \mathrm{MPa}$ obtained from the intercept of the plot shown in figure 7. It may be worth mentioning here that similar observations have also been reported earlier in a Fe-Mn-Al-C alloy with $\sim 1.72 \% \mathrm{C}$ [18] exhibiting a

Table 2. Effect of carbon on the mechanical properties of Fe-7 wt.\% Al-based steel.

\begin{tabular}{|c|c|c|c|c|c|c|c|c|}
\hline \multirow[b]{2}{*}{ Steel } & \multirow[b]{2}{*}{$\begin{array}{l}\text { Nominal } \\
\text { composition } \\
\text { (wt.\%) }\end{array}$} & \multirow[b]{2}{*}{$\begin{array}{l}\text { Density } \\
\left(\mathrm{g} \mathrm{cc}^{-3}\right)\end{array}$} & \multicolumn{3}{|c|}{ Hardness $\left(H_{\mathrm{v}}\right)$} & \multicolumn{2}{|c|}{ Specific tensile strength (MPa cc g ${ }^{-1}$ ) } & \multirow[b]{2}{*}{$\%$ elongation } \\
\hline & & & $\begin{array}{l}\text { Bulk } \\
\text { measured } \\
(30 \mathrm{~kg})\end{array}$ & $\begin{array}{l}\text { Matrix } \\
\text { micro } \\
(10 \mathrm{~g})\end{array}$ & $\begin{array}{c}\text { Bulk } \\
\text { calculated }\end{array}$ & UTS & YS & \\
\hline S1 & $0.012 \mathrm{C}$ & $7.23151 \pm 0.0014$ & $193 \pm 5$ & $193 \pm 5$ & 193 & $67.21 \pm 3.3$ & $55.04 \pm 3.8$ & $21 \pm 1.9$ \\
\hline $\mathrm{S} 2$ & $0.35 \mathrm{C}$ & $7.21024 \pm 0.0020$ & $242 \pm 7$ & $176 \pm 6$ & 227 & $82.08 \pm 3.5$ & $62.39 \pm 4.2$ & $12 \pm 1.7$ \\
\hline S3 & $0.65 \mathrm{C}$ & $7.18254 \pm 0.0021$ & $275 \pm 3$ & $170 \pm 3$ & 267 & $110.77 \pm 4.1$ & $84.95 \pm 4.6$ & $6 \pm 1.5$ \\
\hline S4 & $1.5 \mathrm{C}$ & $7.12591 \pm 0.0012$ & $402 \pm 6$ & $148 \pm 4$ & 384 & $140.31 \pm 4.3$ & $125.03 \pm 5.1$ & $4 \pm 1.3$ \\
\hline S5 & $2.2 \mathrm{C}$ & $7.10318 \pm 0.0018$ & $412 \pm 8$ & $140 \pm 8$ & 396 & $155.62 \pm 4.8$ & $130 \pm 5.4$ & $1 \pm 0.8$ \\
\hline
\end{tabular}

Table 3. Calculated and measured volume fraction of $\mathrm{Fe}_{3} \mathrm{AlC}_{0.5}$, graphite and aluminium (matrix) in $\mathrm{Fe}-7$ wt.\% $\mathrm{Al}-\mathrm{based}$ steel.

\begin{tabular}{|c|c|c|c|c|c|c|}
\hline Steel & $\begin{array}{c}\text { Steel } \\
\text { composition } \\
(\mathrm{wt} . \%)\end{array}$ & $\begin{array}{l}\text { Al present in } \\
\text { the matrix (wt.\%) } \\
\text { calculated }\end{array}$ & $\begin{array}{l}\text { Volume fraction } \\
\text { of precipitate } \\
\left(\mathrm{Fe}_{3} \mathrm{AlC}_{0.5}\right) \\
\text { calculated }\end{array}$ & $\begin{array}{l}\text { Volume fraction } \\
\text { of graphite } \\
\text { calculated }\end{array}$ & $\begin{array}{l}\text { Volume fraction } \\
\text { of precipitate } \\
\left(\mathrm{Fe}_{3} \mathrm{AlC}_{0.5}\right) \\
\text { measured }\end{array}$ & $\begin{array}{l}\text { Volume fraction of } \\
\text { graphite measured }\end{array}$ \\
\hline S1 & $0.012 \mathrm{C}$ & 7 & - & - & - & - \\
\hline $\mathrm{S} 2$ & $0.35 \mathrm{C}$ & 5.4 & 12.46 & - & $12.84 \pm 1.6$ & - \\
\hline S3 & $0.65 \mathrm{C}$ & 4.1 & 23.13 & - & $26.04 \pm 2.8$ & - \\
\hline S4 & $1.5 \mathrm{C}$ & 0.3 & 53.40 & - & $54.64 \pm 2.4$ & - \\
\hline S5 & $2.2 \mathrm{C}$ & Nil & 56.97 & 6 & $57.10 \pm 2.5$ & $6.12 \pm 2.1$ \\
\hline
\end{tabular}


complete $\kappa$-pearlite structure with inter-carbide spacing being varied through different heat treatments. The $\sigma_{0}$ value reported in this steel is $\sim 477 \mathrm{MPa}$, which is marginally higher than $\sigma_{0}$ i.e., $\sim 435 \mathrm{MPa}$ obtained in the present study. The higher value reported may be attributed to the presence of $\mathrm{Mn}$ in the $\mathrm{Fe}-\mathrm{Mn}-\mathrm{Al}-\mathrm{C}$ alloy [18].

\subsection{Fracture behaviour}

Fracture features of tensile samples of all the steels are presented in figure 8. Steels with $0.012-0.35$ wt.\% carbon displayed coarse cleavage facets, while mixed mode features (fine dimples and smaller cleavage steps) are observed in $0.65-2.2$ wt. \% carbon steels. Fracture is generally by cleavage in ferritic $(\mathrm{Fe}-\mathrm{Al})$ steels where grain boundaries act as the main resistance to dislocation motion $[19,20]$. Thus, lowcarbon $\mathrm{Fe}-\mathrm{Al}$ steels are expected to fail by cleavage as these steels have coarse grain size and the resistance is caused by a large number of dislocation pile-ups at the grain boundary which leads to the coarse cleavage fracture [19]. The lower spacing of the inter-pearlite nodule or $\mathrm{Fe}_{3} \mathrm{AlC}_{0.5}$ carbide in steels S3-S5 within the grain has effectively reduced the dislocation pile-up length which resulted in smaller cleavage steps and fine dimples. With an increase in carbon content, there is a progressive decrease in ductility which is due to

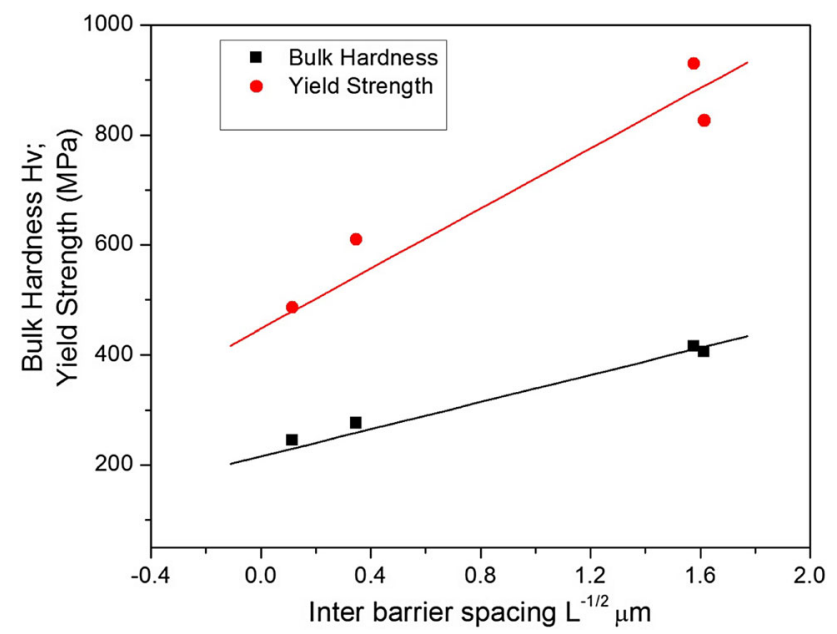

Figure 7. Plot of yield strength and bulk hardness as a function of inverse square root of an average inter-barrier spacing $L$ of different steels.
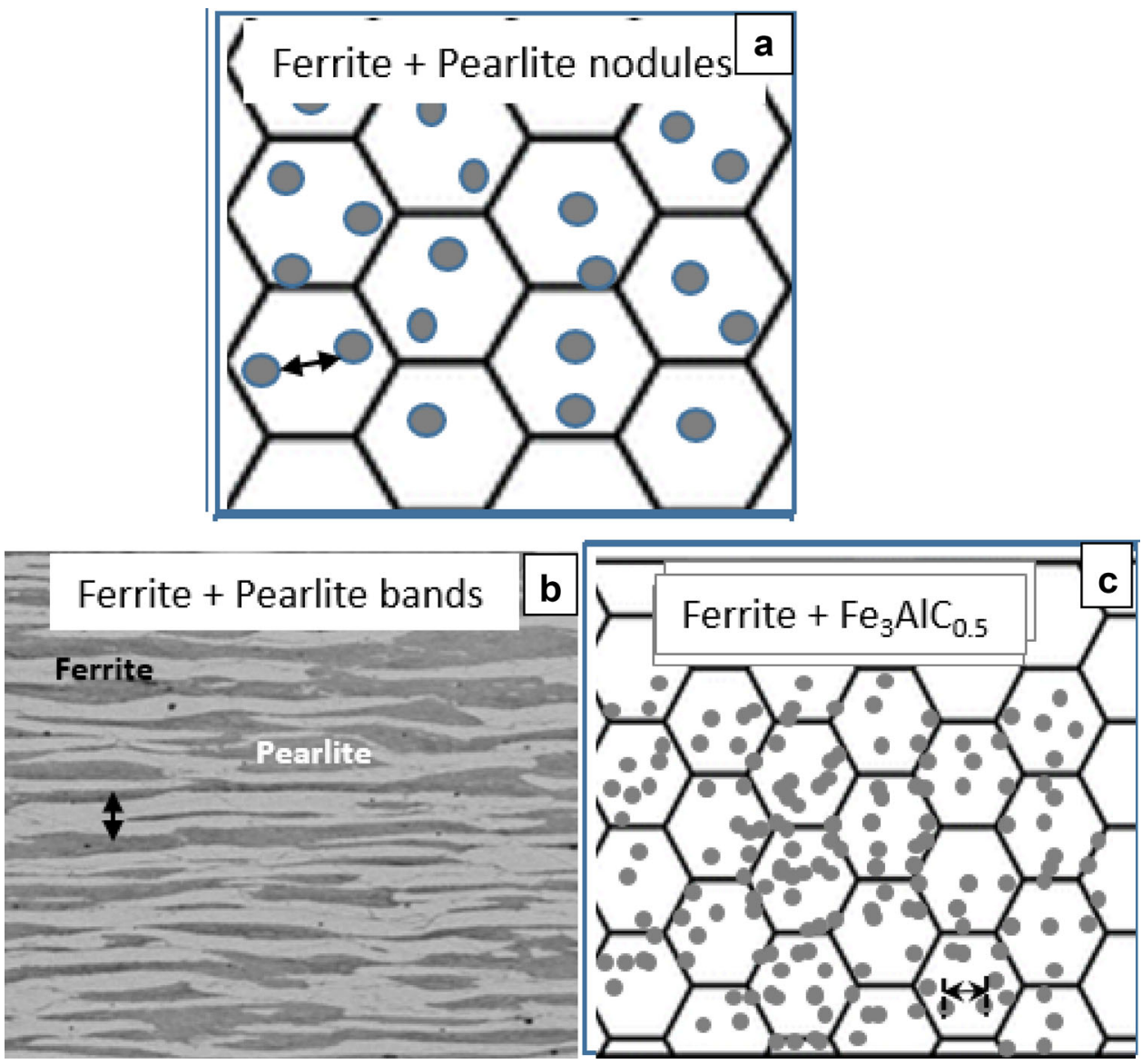

Figure 6. Schematic of various phases present in steels (a) S2, (b) S3, (c) S4 and S5 and their respective inter-barrier spacings. It is the average spacing of $\kappa$-pearlite nodule in steel $\mathrm{S} 2$, average spacing of $\kappa$-pearlite bands in steel S3 and the average carbide spacing in steels S4 and S5. 

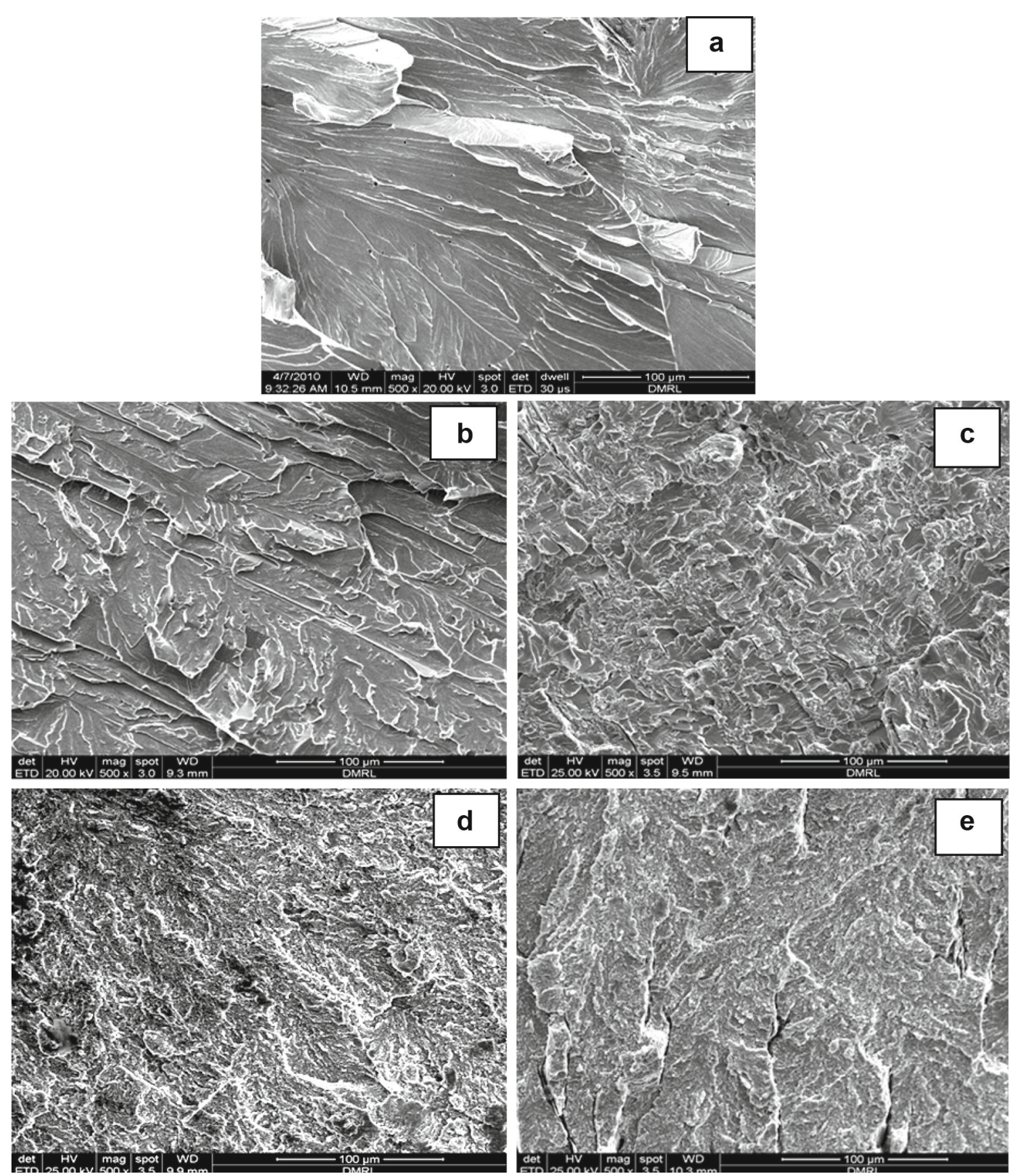

Figure 8. SEM photographs showing the tensile fracture of Fe-7 wt.\% Al-based steel with (a) 0.012, (b) 0.35, (c) 0.65 , (d) 1.5 and (e) 2.2 wt.\% carbon.

the increased incidence of void nucleation and premature interlinkage of voids nucleated at the carbide-matrix interface.

\subsection{Comparison of properties of lightweight steels from literature}

Steels based on the $\mathrm{Fe}-\mathrm{Al}$ system are inherently ductile, but steels with $\mathrm{Al}>7 \mathrm{wt} \%$ suffer from environmental embrittlement during melting, processing as well as testing of the steels [1-4]. Figure 9 shows the properties of steels with different $\mathrm{Al}$ as well as with small $\mathrm{Mn}$ content albeit with similar carbon content. Further, these steels are processed under similar conditions. As discussed above, steels $\mathrm{a}, \mathrm{b}$ and $\mathrm{c}$ with Al 9 wt.\% exhibited poor ductility as these steels are prone to environmental embrittlement. Steels d and e with a small content of Mn content (4-6 wt.\%) have shown a good combination of tensile properties as $\mathrm{Mn}$ has the solubility in both the matrix as well as $\kappa$-carbide precipitates and enhances the properties by solid solution strengthening. 


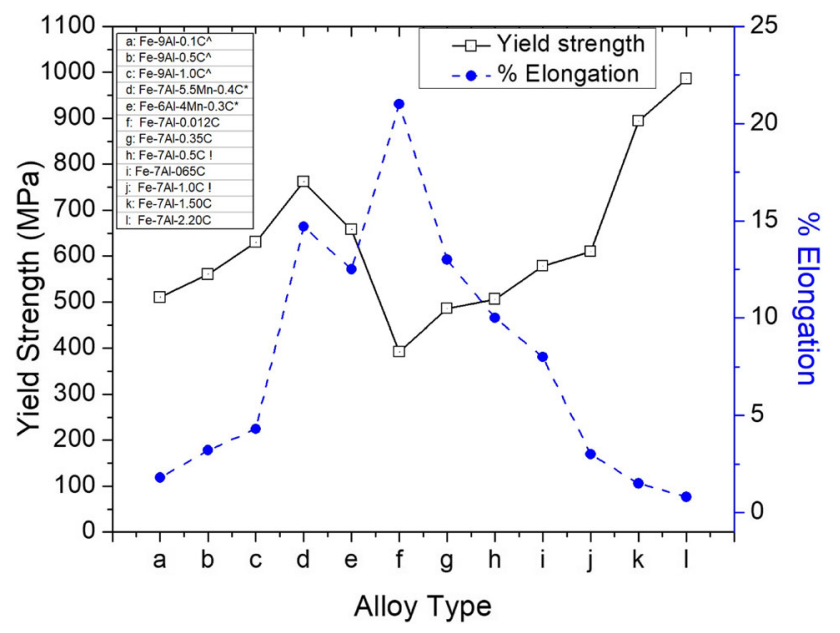

Figure 9. Comparison of yield strength and ductility of lightweight steels from the literature $[6,8,11]$.

Nevertheless, these steels suffer from processing problem i.e., they are prone to cracking during hot-rolling [11-13]. Steels $\mathrm{f}, \mathrm{g}, \mathrm{i}, \mathrm{k}$ and 1 are the steels of present research. Steel g with 0.35 wt.\% $\mathrm{C}$ has shown a good combination of strength and ductility. The ductility of this steel under hot-rolled and annealed conditions is over $12 \%$ which is the minimum required for the formability operation of the steels. Steels with higher carbon content $(\mathrm{C}>0.5$ wt.\%) have shown better tensile strength, but suffer from poor ductility which has been attributed exclusively to the increase in the volume fraction of $\kappa$-carbide precipitates.

\section{Conclusions}

1. Fe-7 wt.\% Al-based low-density steel S1 exhibit a single-phase microstructure of $\mathrm{Fe}-\mathrm{Al}(\alpha)$, whereas steels S2 and S3 exhibit a two-phase microstructure containing ferrite and к-pearlite. On the other hand, steels S4 and S5 exhibit a complete $\kappa$-pearlite structure consisting of the dispersion of globular $\mathrm{Fe}_{3} \mathrm{AlC}_{0.5}$ carbides in a matrix. In addition, the microstructure of steel S5 exhibits a very small volume fraction of the graphite phase.

2. The bulk hardness as well as the specific strength increase significantly with an increase in carbon content. The yield strength as well as hardness of the steels with different carbon contents can be correlated well with the inter-barrier spacing in different steels.

3. Steel S1 exhibited excellent (21\%) ductility. However, the addition of carbon has resulted in significant reduction in ductility (21 to $0.8 \%$ ). The progressive decrease in ductility can be attributed to increased incidence of void nucleation and premature interlinking of voids nucleated at the carbide-matrix interface.

\section{Acknowledgements}

We are thankful to the Defence Research and Development Organization (DRDO), Ministry of Defence, New Delhi, for the funding. We wish to express our gratitude to Dr Vikas Kumar, Director, DMRL, Hyderabad, for his interest and granting permission for this publication.

\section{References}

[1] Rana R 2014 JOM 661730

[2] Rana R, Lahaye C and Ray R K 2014 JOM 661734

[3] Pramanik S and Suwas S 2014 JOM 661868

[4] Khaple S, Sankar M, Baligidad R G and Satya Prasad V V 2010 ISIJ Int. $\mathbf{5 0} 1483$

[5] Herrmann J, Inden G and Sauthoff G 2003 Acta Mater. 512847

[6] Khaple S, Baligidad R G, Satya Prasad V V and Satyanarayana D V V 2015 Mater. Sci. Technol. 311408

[7] Jimenez J A and Frommeryer G 2011 J. Alloys Compd. 509 2729

[8] Baligidad R G and Satya Prasad V V 2007 Trans. Indian Inst. Met. 601

[9] Palm M and Inden G 1995 Intermetallics 3443

[10] Raghavan V 1987 Phase diagrams of ternary iron alloys, Part I (OH USA: ASM Metals Park)

[11] Sang Y S, Hackcheol L, Han S Y, Chang-Hyo S, Kayoung C, Sunghak L et al 2010 Metall. Mater. Trans. A 41138

[12] Seung Y H, Sang Y S, Sunghak L, Nack J K, Jai-Hyun K and Kwang-Geun C 2011 Metall. Mater. Trans. 42A 138

[13] Sohn S S, Lee B J, Lee S and Kwak J-H 2013 Acta Mater. 61 5626

[14] Schneider A, Falat L and Sauthoff G 2005 Intermetallics 13 1322

[15] Prakash U 2008 Indian Inst. Met. 61193

[16] Satya Prasad V V, Khaple S and Baligidad R G 2014 JOM 66 1785

[17] Baligidad R G, Radhakrishna A and Prakash U 1998 Mater. Sci. Eng. A 257235

[18] Ishii H, Ohkubo K, Miura S and Mohri T 2003 Tetsuo Mater. Trans. 441679

[19] Chen J H and Cao R 2015 Micromechanism of cleavage fracture of metals: a comprehensive microphysical model for cleavage cracking in metals (Oxford, UK: Elsevier Publication)

[20] Calcagnotto M, Ponge D, Adachi Y and Raabe D 2009 Proceedings of the 2 nd International symposium on steel science (Kyoto, Japan: The Iron and Steel Institute of Japan) 